\title{
Games in Learning: Shedding Light on a Problematic Taxonomy
}

\author{
T.R. Beatman ${ }^{1,2, *}$ and R.J. Duff ${ }^{1}$ \\ ${ }^{1}$ Department of Biology, University of Akron, Akron, OH 44325-3908, U.S.A. \\ ${ }^{2}$ Integrated Bioscience Program, University of Akron, Akron, OH 44325-3908, U.S.A.
}

\begin{abstract}
The use of games as tools for learning has been a paradigm of great interest for over fifty years. Several terms have emerged to describe disciplines that study and apply this paradigm. Many of these terms may be synonymous or have overlapping uses or have multiple definitions within different disciplines. The literature was surveyed for the definitions terms relating to this paradigm. Their working definitions and relationships are discussed. Through both a survey of the literature and a novel variant of sorting activity, the Item Definition Semantic Sort (IDSS). It is shown that individual item definitions do not semantically cluster together by corresponding term. This indicates both a lack of consensus on terms' definitions, and of clarity between terms. The umbrella term Games in Learning (GiL) is coined to integrate the disciplines and products within this design paradigm. Games in Learning is defined, "Research and work involving the use of games, in whole or in part, as tools to improve motivation, engagement, and/or understanding in learning". The rationale for the term is elaborated, and the major functional divisions found within.
\end{abstract}

Keywords: Serious Games, Gamification, Game-based Learning, Semantic analysis, Card Sort, Semantic Taxonomy.

Received on 14 November 2018, accepted on 07 December 2018, published on 04 January 2019

Copyright (C) 2019 T.R. Beatman and R.J. Duff, licensed to EAI. This is an open access article distributed under the terms of the Creative Commons Attribution licence (http://creativecommons.org/licenses/by/3.0/), which permits unlimited use, distribution and reproduction in any medium so long as the original work is properly cited.

doi: 10.4108/eai.13-9-2018.156151

\section{Introduction}

The topic of using games, and more recently, gameful experiences, as learning tools has been a subject of great interest to educators for decades. The first pages of [1] summarizes the state of the field, then and now, nicely:

Among recent innovations, educational games offer great promise of furthering this change [to experiential learning]. Not only are they fun, but they require that all players share in making decisions throughout the game. Unfortunately, educational games are not well understood. They are not yet widely available, and experience with them is necessarily limited; as a result, a mystique surrounds the technique. To complicate matter, the use of games implies a seeming irreverence toward education.
Educational games are neither esoteric nor frivolous. But they differ enough from most other classroom activities to raise questions about the role of the teacher, the time and space required, how to evaluate what games teach students, and the benefits and drawbacks of using games. These and other operational problems will be discussed in ensuing chapters. But the primary question remains: Can educational games, which often resemble entertainment games, be employed for serious purposes in the classroom? A survey of the origin and history of serious games may help allay initial doubts about the viability of the technique.

Nearly fifty years have passed, yet the state of things is much the same, often focused on building the rationale for using games in learning. For example, Wiktionary provides under its definition of games the example sentence: Games in the classroom can make learning fun. Multiple disciplines 
have emerged into common use, including gamification, serious games, digital game-based learning, gameful design, e-learning, edutainment games, and more (see box 1). In these disciplines, there exists a dizzying array of terms. More confusingly, the definitions of these disciplinary terms are often nested within one another to the point that their differences are difficult to parse (see Figure 1, taken from [2]). Despite this, multiple disciplines are often used in isolation with little effort to consolidate or even reconcile the relationships between them.

A major challenge in mapping the definitions and relationships is this use of terms. Scientific/disciplinespecific terms are meant to provide an economy of language, to allow concepts to be expressed succinctly. Terms transform broadly descriptive words and phrases into specific meanings in scientific contexts [3]. Unfortunately, such terms still suffer from shifts (semantic changes) in both meaning (denotation) and nuance (connotation) [4. These semantic changes can lead to problematic differences in the use of a term, especially if similar changes are occurring with similar terms in parallel. These sorts of shifts directly impede the concise and effective communication terms are designed to allow. These semantic changes are frequently found when discussing the disciplines relating to the use of games in whole or part in learning contexts.

Although there is overlap in their structural (form) and functional (psychology) paradigms, a concise, cohesive, or comprehensive umbrella term to describe the entirety of research involving games in whole or in part as tools for learning is lacking. This makes elaborating the many disciplines de rigueur when discussing games in learning. A search into these disciplines quickly reveals over a dozen headers, design disciplines, and pedagogical perspectives. Further problems arise in understanding the relationships between these terms, as their common usage in the literature is often in isolation from one another, and their definitions vary. Recent studies show misuse and misplacement of meaning even for terms that most frequently appear in the literature [5]. While such confusion has persisted, the promise of these disciplines as a whole suggests it is worth continuing to find ways forward. To that end we hope to foster better communication.

This paper is a review synthesis of the numerous disciplines which examine and develop products which use games, in whole or in part, as tools to produce motivation and engagement in learning. The definitions of these disciplines are examined comparatively using an item definition semantic sort (IDSS), a novel variant of card sorting, to expose the significant overlap and synonymy between them, and lack of consistency within individual terms' definitions. To address this problem, the umbrella term, Games in Learning, is coined. Games in Learning (GiL) describes any and all works that use games, in whole or in part, as tools to improve motivation and engagement in learning. The intent of this umbrella term will serve to aid in joining these disciplines into a transdisciplinary space. These disciplines conspicuously share common structural and functional paradigms but have had no means to quickly and easily refer to them as a common group nor has there been a comprehensive attempt to map out their relationships in detail.

1. Digital Game-based Learning

2. Educational Games

3. Edugames (Edu Games, Edu-games; short for either Educational Games or Educational Computer Games)

4. Edutainment Games

5. Elearning

6. Game-assisted Learning

7. Game-based Learning

8. Game-based Teaching and Learning

9. Gameful Design/Experiences for/in learning

10. Games and Learning

11. Games for Change

12. Games for Learning

13. Gamification of/for/in Learning

14. Instructional Games

15. Learning Games

16. Persuasive Games

17. Serious Educational Games

18. Serious Games

19. Simulation \& Games*

Box 1. Terms relating to the use of games in whole or in part in learning

\section{Methods}

\subsection{Definition Search}

Sixteen terms used to describe research disciplines and applications are examined here: Digital Game-based Learning; Educational Games; Edugames; Edutainment Games; Game-assisted Learning; Game-based learning; Game-based Teaching and Learning; Gameful Design*; Games for Learning; Gamification*; Instructional Gaming; Learning Games; Persuasive Games; Serious Educational Games; Serious Games*; Simulation [\&] Games (Terms denoted with an asterisk are also used in noneducation applications). Approximately half of these emerged as terms since the start of the 21 st century.

Definitions were found through examining original source literature, and recent well-cited articles for occurrences of the relevant term in conjunction with a clearly provided definition. Terms with multiple definitions were assessed for commonalities and combined when possible. A total of 50 definitions were sourced for 15 terms, of which one term and definition served as an outgroup to determine the height at which to cut clusters. 


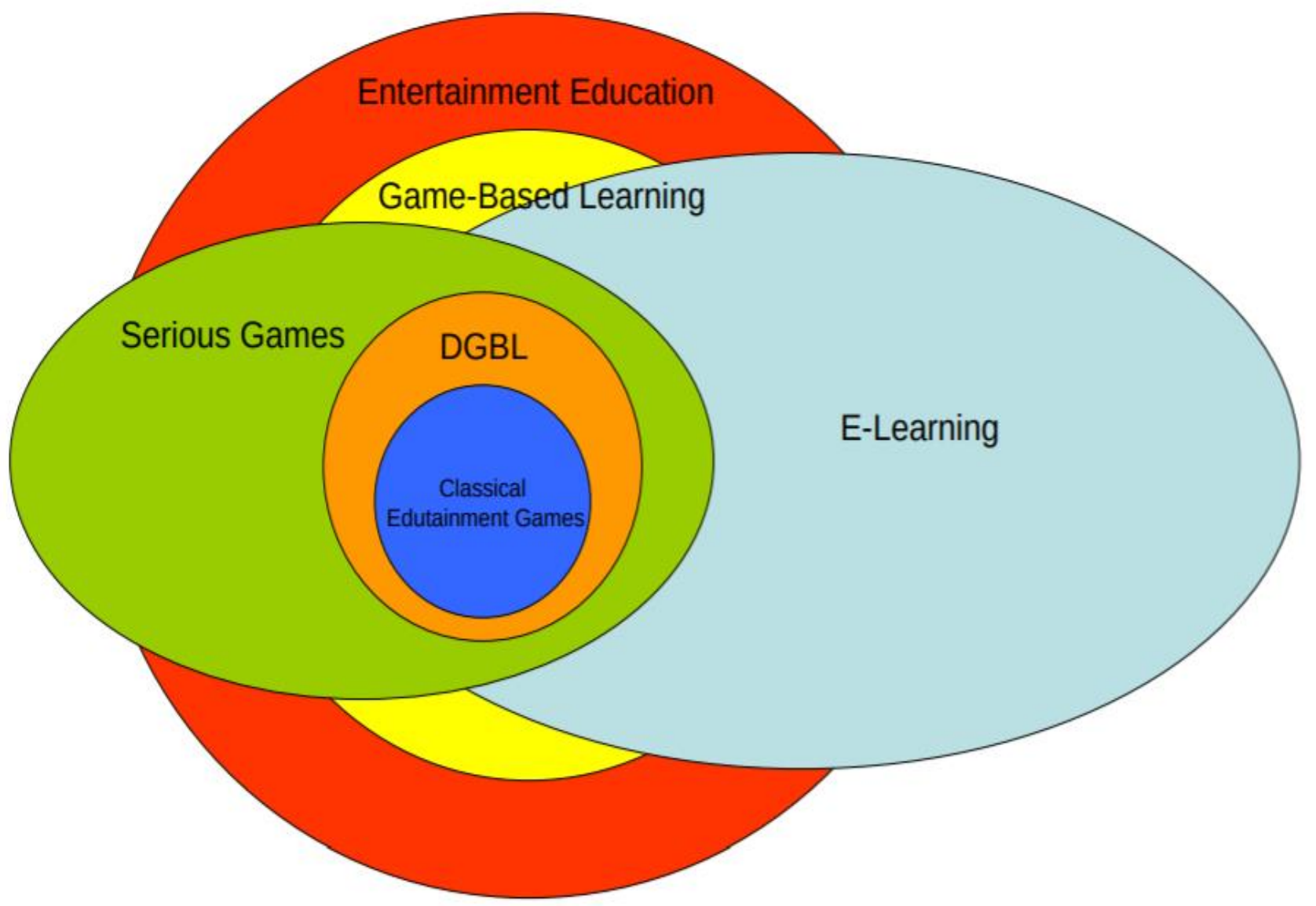

Figure 1. The original caption was, "The relations between serious games and similar educational concepts" (from [2]). While this diagram depicts the overlaps between numerous Games in Learning fields, it fails to readily provide any discrete information as to the nature of these overlaps.

\subsection{Item Definition Semantic Sort}

The relationships of the various disciplines found in the initial search were delineated using an Item Definition Semantic Sort. Unlike typical semantic card sorts, where the items sorted are individual words/terms, the items were instead definitions that correspond to the terms of interest. 50 individual definitions, covering 13 different GiL terms, were blinded to their corresponding terms, and printed onto slips or cards, and then sorted by volunteers based on perceived semantic similarity. Volunteers were sourced from students, staff, and faculty at the University of Akron.

Sorters were given limited guidance on ways in which items could be sorted, with enough prompts to understand to sort them based on whether they described the same or similar concept. The 25 sorts were performed by a number of volunteers from the University of Akron. Each was provided with an instruction sheet as well as the blinded definitions printed on slips or cards (see supplementary information). The card sort also allowed for participants to describe the rationale for their groupings, and to select exemplar definitions for each group. The explanatory rationales were used solely to identify and split groupings whose purpose were to contain perceived outliers; the identified exemplars were not used in any part of the analysis in this study.

Sorts were compiled into a co-occurrence matrix, transformed into Euclidean distances and then analyzed by hierarchical cluster analysis using Hierarchical Clustering v1.0.5 in Free Statistics Software v1.2.1 [6]. The output cladogram from the program was then used as a basis for a cladogram containing more information regarding the terms each individual item corresponds to, to facilitate visualization of the results (Figure 2).

\section{Results}

\subsection{Definitions}

\section{Serious Games}

Abt first described games that could be played seriously, and coined the term "Serious Games", describing them as "games [that] have an explicit and carefully thought-out educational purpose and are not intended to be played primarily for amusement [7, p. 9]. This does not mean that serious game are not, or should not be, entertaining". In the past two decades, a number of other definitions have emerged. As [8] highlights, these definitions frequently are reductive 
variations on "games that have a purpose beyond entertainment" [9,10,11,12,13,14,15,16.17]. As such, while Abt's definition is similar, it does emphasize the functional role of the use of an entertaining medium as leverage for education (or training).

Functionally, the purpose of the term Serious Games, classically, was to emphasize the use of games for serious purposes. The many definitions found frequently fail to incorporate the fact that since games are intended, by design, to be enjoyable activities, they can then be used as more engaging educational tools. [12]'s definition is exclusively referring to digital games (2006) but can be easily revised to a more meaningful and broader definition, "about leveraging the power of ... games to captivate and engage end-users for a specific purpose, such as to develop new knowledge and skills". Serious Games functions effectively as the broadest term for the use of games for non-entertainment purposes, including but not limited to education and learning.

Serious Educational Games, Games for Learning, Educational Games, Edugames, Edutainment Games

Other disciplines exist which either significantly overlap with Serious Games or are wholly nested within them. Serious Educational Games as a term has been used to specify Serious games used for K-20 educational purposes [14, 18], a clarity which can find use when needing specificity while discussing the full array of Serious game applications, but unnecessary when a learning context is clear.

Educational Games, Edutainment Games, Games for Learning, and Edugames show similar context-dependent redundancy. Edutainment, as a descriptor for games, most notably features this, as the entertainment/engagement value of games is, fundamentally, the entire purpose of using them for educational purposes. Educational Games is most frequently used as a descriptive term, rather than as the name of a discipline, like Games for Learning as well as Learning Games (both discussed below). Edugames is frequently found as an abbreviation for Educational Games, but also has usage in isolation in foreign language publications of unknown quality.

\section{Digital Game-Based Learning, Game-Based} Learning, \& Game-Based Teaching \& Learning The term Digital Game-based Learning, much like Abt's Serious Games, had its origins as the eponymous title of [19]. [20] defined it (drawing from both Digital Game-based Learning and Serious Games) as game applications that have defined learning goals. [13], in an overview of Serious Games refers to a Wikipedia article (the provenance of which is unknown) that explicitly defines game-based learning as "a branch of serious games that deals with applications that have defined learning outcomes", and then clarifies Digital Gamebased learning being a more specific term for such games that are digital. [12] also refers to game-based learning and serious games as equivalents.

What is significant, however, is the connotation found when the phrase game-based learning is used: it frequently is used to exclusively describe digital/video/computer games. The term Digital Game-based learning notably predates the occurrence of Game-based learning, and the way that Gamebased learning is used, frequently preferred over Digital game-based learning, suggests that rather than it occurring as a more inclusive descriptor of game applications that have defined learning goals, there remains an implicit element of those games being digital. As a result, while the term Gamebased learning would appear to be term with broader uses than its predecessor, practice shows that it is moreso an abbreviation of its antecedent.

Parallel to these terms' usages, "Game-based Teaching", or "Game-based Teaching \& Learning" have been found in more recent literature. Use suggests a primary meaning focused on actual use by instructors (D)GBL; it remains unclear what purpose this distinction serves.

\section{Instructional Games, Game-assisted Learning}

Both of these terms have been used historically in the literature primarily as descriptive language and are typically either used synonymously with "computer-assisted learning" or game-based learning. Game-assisted Learning's definition [21], "the outcome of integrating effective learning principles into game environments for the purpose of utilizing engaging elements of games as a means for improving the quality of education" is noteworthy as it explicitly details using the affordance of games in learning. Instructional Games, in contrast, in their definition [22, 23, 24], "any interactive, digital game that is designed specifically to facilitate the achievement of a specified set of learning outcomes that meet educational goals" features a digital qualifier and seems primarily prescriptive to the outcome rather than the means. Both terms are functionally the same as the common conception of game-based learning.

\section{Games for Learning}

Abt used the phrase "games for learning" in an early paper, later published as a chapter in [25], however it only occurs recently as a term, with the definition "games specifically designed for learning as opposed to the use of games in learning" [26]. It becomes clear that while this term intends to distinguish games built for education/learning from COTS games used in learning contexts, this distinction seems mostly a matter of specificity of product type within the broader scope of the established research.

\section{Gamification \& Persuasive Games and Gameful Design/Experiences}

The term gamification and its applications have gained special interest over the past decade, the definition being "The use of game-elements in non-game contexts" [27]. While whole games have been in use for applied training and education, the application of game-elements or game-layer to improve non-games is a recent trend. The contrast, however, between its definition and actual applications, proves to be problem.

Major success in gamification has been shown using the "game-elements" of points/high scores, badges, and achievements. These concepts have been used historically as 
sources of extrinsic motivation in games (arcade games, Xbox, etc.), despite a central premise/appeal of using games, in whole or in part, is that they can produce intrinsic motivation as a result of being fun [28]. These prominent examples of so-called game-elements are in fact hardly so; practitioners of this form of gamification often respond to this criticism with a general indifference to this mismatch. This can only be described as a use of language in bad faith. Numerous authors (summarized in [29] have had issues with the exploitative nature of gamification's common uses and the problem being that while the definition precludes use in games, the layer being used in non-game contexts for extrinsic motivation can and is being used in games. These pseudogame-elements are more representative of operant conditioning practices [30]. This reductive use of basic operant conditioning as a key component of gamification minimizes the other game-elements more fundamental to gaming experiences, and their continuing use could undermine the concept fundamentally.

In part as a response, new terms and approaches to gamification have arisen. Persuasive Games was a term coined by [31], seeking to not only highlight the operant conditioning rampant in gamification by renaming it exploitationware, but to provide a less jaded alternate. Gameful Design, in contrast to gamification, focuses on gamefulness as a design goal, rather than a design strategy [32]. [33 \& 34] provided the following definitions: The use of game design elements in non-game contexts with the goal of achieving long-term effects based on intrinsic motivation; designing systems that are intrinsically motivating and fun to use, by applying those techniques that game designers use to keep the players immersed and engaged. Both definitions focus on using game design techniques or elements, with the targeted goal of making systems that produce intrinsic motivation. Gameful Design, as a term, seeks to address the contention surrounding Gamification. While the term Persuasive Games has had limited traction outside of pointing to gamification's flaws, Gameful Design has succeeded in a more pointed effort in referring to using definitive gameelements for nongame applications.

Broadly, gameful design as a practice is the more commonly accepted term for what gamification purports to be, especially among those who dislike the current outputs of the gamification movement, which is itself rife with definitional problems (explored in depth in [35]).

\section{Learning Games}

Learning Games has definitions which are far more explicit in their functional relationship between games and learning. For example, [36] describes, "A learning game is supposed to provide structured and immersive problemsolving experience that enables the development of both knowledge and 'ways of knowing' to be transferred to the situations outside of the original context of gaming or learning.". This definition not only recognizes the ability of learning games to fail (though the use of the phrasing is supposed to), but also the goal of the takeaways of learning games expanding beyond the framing of both original contexts.

\subsection{Card Sort}

The card sort produced 11 in-group clusters (Figure 2), with each cluster containing between two and nine cases/items. While a single cluster contained cases/items all corresponding to a single term, no individual cluster was composed solely of all cases/items of a single term. Card item 44 , the definition of Games with a Purpose, "a class of games in which people, as a side effect of playing, perform tasks computers are unable to perform" served as a functional outgroup in the card sort. Because of this, the clusters were cut at the height at which this term definition connected to other term definitions in the sort (the red dashed line in Figure 2).

The lone single-term cluster contained definitions for serious games. As serious games as a discipline is broadly inclusive of games used for purposes beyond solely entertainment (more details in section below), it is unsurprising to find that its definitions both cluster together and can be found scattered throughout the other items in the taxonomy. While the taxonomy generated does show some hints of the relatedness of certain terms (most notably the common clustering of gamification and gameful design, as explored elsewhere in this article), there is an evident lack of clustering of definitions by the terms they correspond to. This pattern clearly illustrates a lack of consistency and coherency in the meaning of individual terms, but more importantly a lack of distinction between disparate terms that, functionally, would be expected to have clear and different meanings to justify their usage. 


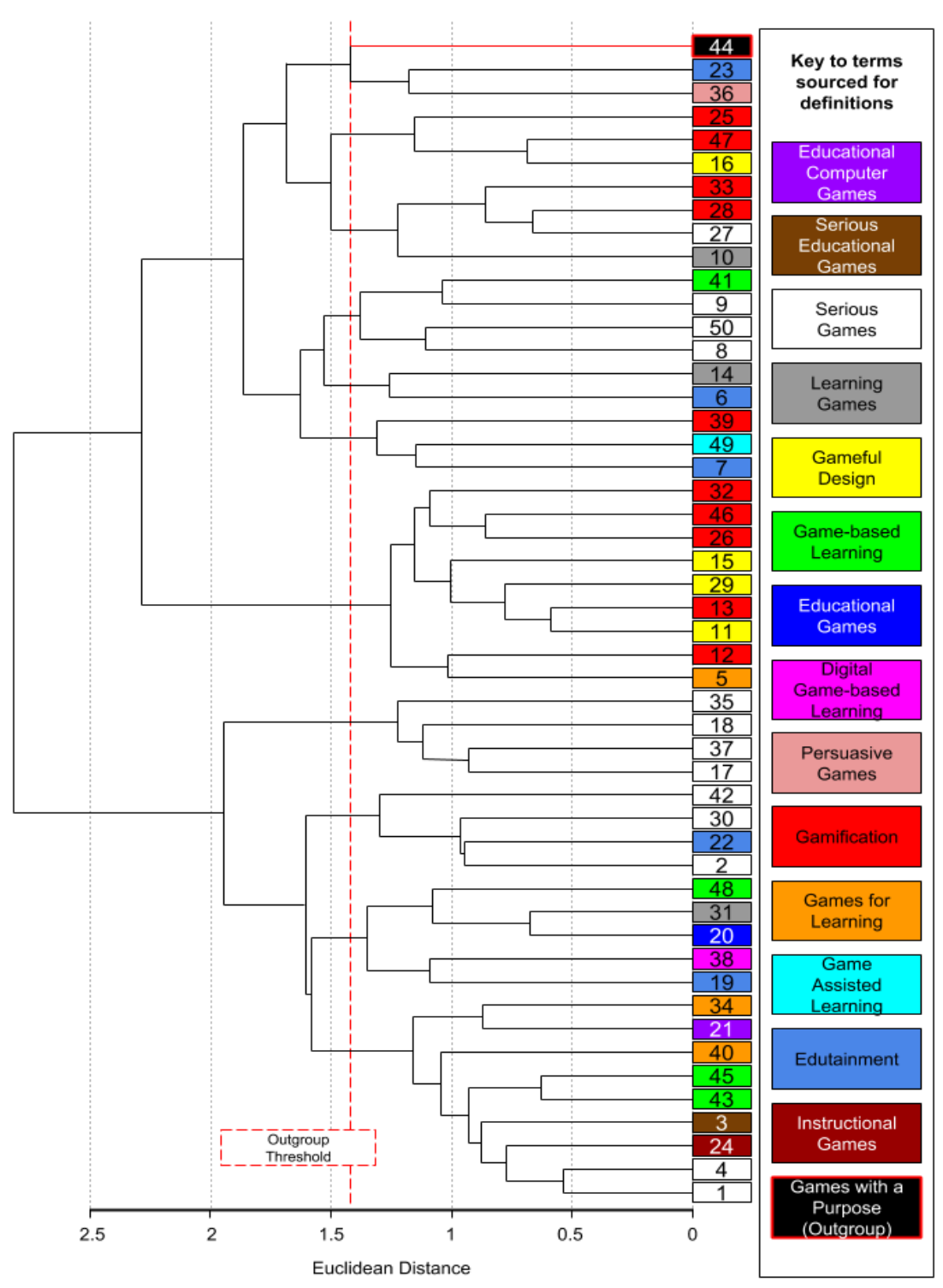

Figure 2. Dendrogram of item definition interrelationships. Branch length is Euclidean distance, color of items corresponds to associated terms in key part as tools to improve motivation and engagement in learning.

\subsection{Relationships}

Fundamentally, when discussing using Games in Learning, the topic is the use of games in a learning application, as opposed to the use more broadly for other applications (as Serious Games' denotation typically allows) or use solely as an entertainment medium.

\section{Whole-Partial Divide}

There are two major design perspectives found in Games in Learning. These perspectives, what can be called the whole-partial divide, are not limited to education applications. They consist of the use of either games in their whole entirety (full-fledged games) or in parts (non-game activities featuring game-elements), applied in nongame contexts (Figure 3A). Whole game applications are typically described as Educational or Learning Games; Serious games is also a wellestablished term but is often considered to be more inclusive as it distinguishes training from education. The partial-game approach can be further subdivided dependent on whether gamefulness is a design strategy (Gamification proper) or a design goal (Gameful Design/Experiences) (Figure 3B). Functionally, this divide can be expressed as a difference in whether a game layer is added to an application or incorporated inextricably. These differences are elaborated upon above.

\section{Discussion}

Through both the survey of the literature and the card sort analysis, the disjointed state of the current disciplines of study becomes rapidly apparent. While each individual discipline is not intrinsically disrupted by this, it notably prevents productive cross-fertilization and organization between disciplines, and as such prevents the sorts of consilience and collaboration that could greatly benefit future research. To begin addressing this challenge, the term Games in Learning is coined to frame the commonalities in form and function of the disciplines/disciplines which use games in whole or in 


\section{Media Forms}

[37] discussed the relationships between several the disciplines mentioned in this paper and sought to recognize Simulation/Gaming as a discipline that included “...simulation, gaming, serious game, computer simulation, computerized simulation, modeling, agent-based modeling virtual reality, virtual world, experiential learning, game theory, role-play, case study, and debriefing." His editorial also sought to fasten the concept of simulation/gaming explicitly to computerized forms.

GiL disciplines also feature a notable divide between digital (video/computer games, applications, websites, programs, etc.), and analog (tabletop, board, card, etc.) media. Since the earliest commercial availability of computers, their potential for operating simulations that can be used for

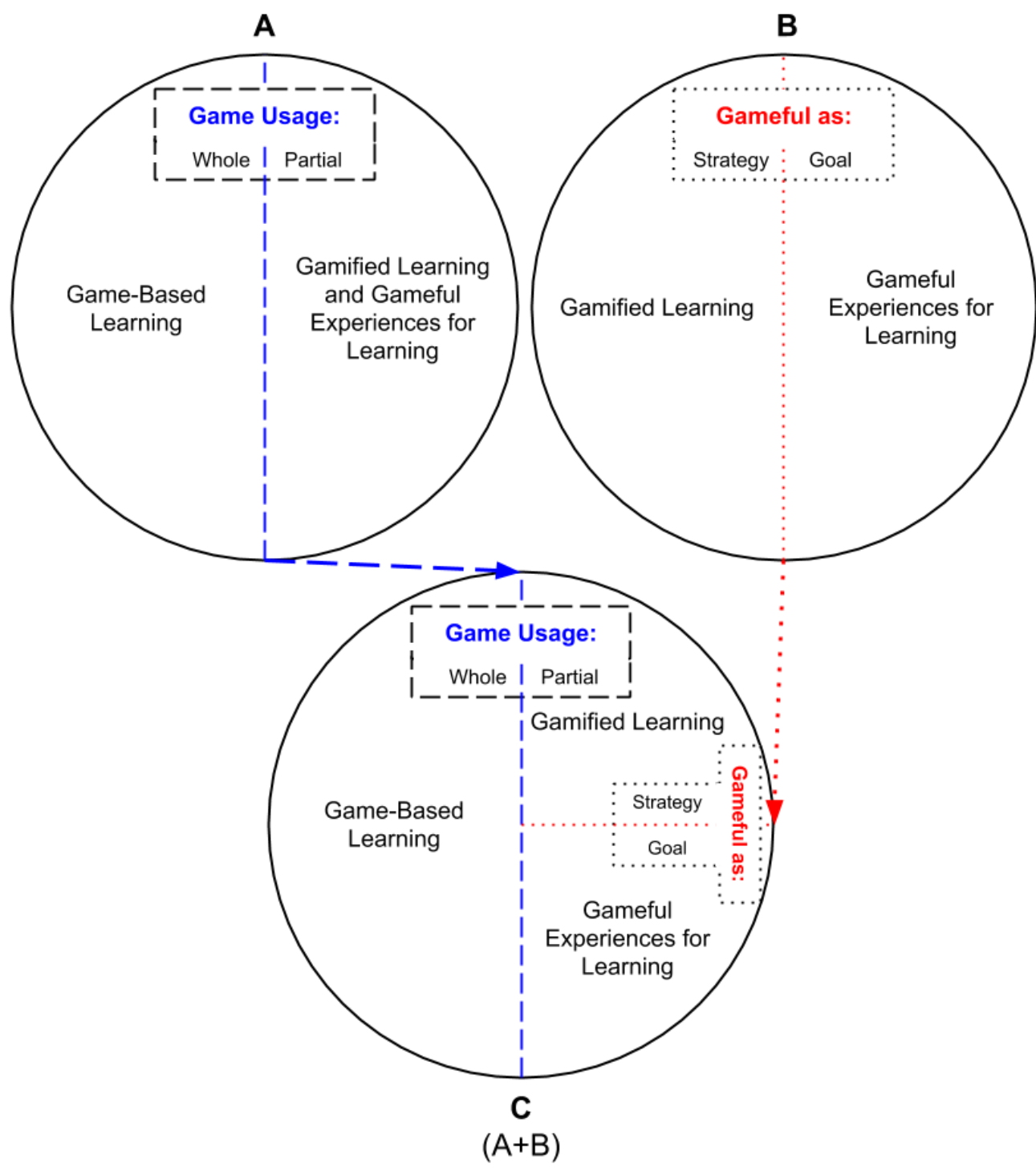

Figure 3. Relationships of game usages $A$ ) Use of games in whole or in part, $B$ ) Perspective of gameful (use of games in part) as design strategy or goal, $C$ ) Diagram combining information found in $\mathrm{A}$ and $\mathrm{B}$ education or training purposes has likely influenced the predominance of using digital games in learning. As a result, the connotation of the word game has changed, leading to it referring exclusively to digital/video/computer games in many cases. In response to this, other disciplines and terms must then explicitly clarify whether they are referring to digital games, analog games, or both, when using the word game either in isolation or as part of a term or research discipline. There remains, however a growing global market for analog (Hobby) games [38, suggesting an underexploited medium for Games in Learning. As such, while there is a divide in medium between analog and digital games, there is limited rationale for a disciplinary division.

\subsection{Games in Learning}

\section{Rationale}

The term Games in Learning was chosen to describe the use of games, in whole or in part, as a tool to produce engagement and motivation in learning, for two major reasons. The first is that it is a novel umbrella term and functionally descriptive, and the second is its precedence in use as a descriptive phrase; both are elaborated below.

Functionally, Games in Learning serves as an inclusive umbrella term to discuss all research which uses the paradigm of games as a tool in learning contexts. Games in learning, even as a phrase rather than a term, has an intuitive meaning. Connotatively, it suggests that the entirely of learning may not take place solely within a game framework, allowing for the broadest nuance of understanding the idea. Effort was taken to not coopt extant terms, or to create a term that forms a competing standard. It allows for an interpretation of the use of games in whole and in part in all learning contexts.

The word learning is used in the term, rather than education, to focus attention on the outcome, rather than the process. As GiL covers products used in structured, unstructured, formal, and informal settings, the natures 


\section{GAMES IN LEARNING \\ What is GiL? \\ The umbrella term describing research and work relating to using whole games \\ or games in part as a tool to produce motivation and engagement of users to learn \\ Why GiL? \\ Current fields that fall into the GiL umbrella are inadequately connected to each other, preventing cross-communication, consilience, and collaboration \\ What is in GiL? \\ Fields including, but not limited to: \\ - Game-based learning \\ - Serious Games \\ - Gamification \\ - Gameful Design \\ - Learning Games}

Box 2. A short summary of the rationale for Games in Learning

of which can vary, but the outcome of learning remains consistent, using the word learning, rather than education/educating, avoids a connotation that implies use solely in classrooms, curricula, and other structured settings.

The historical precedent for Games in Learning is twofold. The first is found in Simulation Games in Learning [39]. This book features a number of relevant chapters on the theory and application of using games in learning. The word Simulation was removed from our term to allow for the maximum breadth of game types, and to include nongame applications (gameful designs, gamification, etc). Secondly, in a more recent writing, [26] in their chapter Games for learning used the phrase "games in learning" as part of their definition of the more specific "games for learning" (bold added for emphasis):

In this chapter we will outline relevant aspects of serious games supporting a learning process. Under the term games for learning we refer to games specifically designed for learning as opposed to the use of games in learning

A broad takeaway should be that the use of descriptive phrases, and the formation of excessive and redundant terms, has generated the quandary that this latest addition seeks to resolve. One could say that we seek to achieve subtraction by addition. Game-based learning was used first as a descriptor before it became a term for a discipline or products from such disciplines, just as serious games, educational games, and others have. Working from this precedent, the occasional descriptive use of "games in learning", often in the format of "using games in learning something", has been adapted as a unifying term to describe the numerous disciplines which occur in the transdisciplinary space of using games in whole or in part in learning. At the very least, it will, as terms intrinsically do, serve as a shorthand to describe the broad paradigm of using games, game and gamelike elements, and gameful experiences, as tools in, for, with, and of learning/education.

\section{Future and Implementation}

Several different terms and disciplines currently in use in the research literature share commonalities, most importantly a shared paradigm of using games, gameful/like/inspired experiences, and game elements as tools for learning. Beyond this, several of the terms used either overlap significantly, or are for all intents and purposes synonymous. While making changes to usage to reduce such redundancy would conceptually be an effective takeaway from this paper, it is recognized that these terms are well established in the literature. It is suggested that, while individual terms may be preferred, that better efforts be made to not only acknowledge their definitions regularly to reduce semantic change, but also their relationships to other disciplines within Games in Learning.

The use of the term Games in Learning extends beyond simply being an inclusive descriptor but serves as a framework to recognize the utility and consilience to be gained in its various subdisciplines' collaboration. Especially as many headings exist in isolation despite sharing similar definitions with others, there seems to be a need for better communication between each community of practice for the betterment of all Games in Learning research, development, design, and practice. Within discussions of Games in Learning products and outcomes, the following labels are recommended to identify whole- or partial-game products. For whole Games in Learning products, the existing Educational/Learning games is both functional, descriptive, and well established in the literature. For partial-game applications, Gameful applications provides clarity that the product is not a game proper, but rather an application with gameful components. Gameful applications can be used more broadly for non-educational applications, but within the context of Games in Learning such clarifications should prove unnecessary.

Future work is needed to further examine the commonalities among disciplines with respect to Games in Learning, and the functional nature in which game-learning can be applied to content-specific learning. While much work has been done in conjoining motivational theories to the rationale of using Games in Learning, there remains many opportunities for improving the design of such products to improve their effectiveness. It remains to be seen whether the various disciplines grouped together here under Games in Learning can effectively recognize their similarities and benefit from one another's' differences. 


\section{Appendix A. Card Sort Definitions}

This table corresponds to the item definitions indicated in the card sort cluster analysis found in Figure 2. Each row provides the number pseudorandomly assigned to each item definition (ordered by first authors surnames alphabetically), the definition extracted from the text, the author(s), the year of publication (references in subappendix A.1), and the term the definition belongs to.

\begin{tabular}{|c|c|c|c|c|}
\hline \multirow{2}{*}{ \# } & \multicolumn{4}{|l|}{ Definition Information } \\
\hline & Definition & Authors & Year & Term \\
\hline 1 & $\begin{array}{l}\text { games [that] have an explicit and carefully thought-out } \\
\text { educational purpose and are not intended to be played primarily } \\
\text { for amusement. This does not mean that serious game are not, or } \\
\text { should not be, entertaining. }\end{array}$ & Abt & 1970 & Serious Games \\
\hline 2 & $\begin{array}{l}\text { electronic/computer-access games that are not designed for } \\
\text { commercial purposes but rather for training users on a specific } \\
\text { skill set }\end{array}$ & Annetta & 2010 & Serious Games \\
\hline 3 & $\begin{array}{l}\text { electronic/computer-access games that are not designed for } \\
\text { commercial purposes but rather for training users on K-20 content } \\
\text { knowledge }\end{array}$ & Annetta & 2010 & $\begin{array}{l}\text { Serious } \\
\text { Educational } \\
\text { Games }\end{array}$ \\
\hline 4 & $\begin{array}{l}\text { games that are expressly designed with explicit educational } \\
\text { purposes }\end{array}$ & Bellotti et al. & 2011 & Serious Games \\
\hline 5 & introduction of game elements in the design of learning processes & Bellotti et al. & 2013 & $\begin{array}{l}\text { Games for } \\
\text { Learning }\end{array}$ \\
\hline 6 & $\begin{array}{l}\text { a hybrid genre that relies heavily on visual material, on narrative } \\
\text { or game-like formats, and on more informal, less didactic styles of } \\
\text { address }\end{array}$ & $\begin{array}{l}\text { Buckingham \& } \\
\text { Scanlon }\end{array}$ & 2000 & Edutainment \\
\hline 7 & $\begin{array}{l}\text { the process of entertaining people at the same time as you are } \\
\text { teaching them something, and the products, such as television } \\
\text { programmes or software, that do this }\end{array}$ & Mclntosh et al. & 2017 & Edutainment \\
\hline 8 & $\begin{array}{l}\text { The application of gaming technology, process, and design to the } \\
\text { solution of problems faced by businesses and other organizations. } \\
\text { Serious games promote the transfer and cross fertilization of } \\
\text { game development knowledge and techniques in traditionally non- } \\
\text { game markets such as training, product design, sales, marketing, } \\
\text { etc }\end{array}$ & Cook & 2005 & Serious Games \\
\hline 9 & $\begin{array}{l}\text { about leveraging the power of computer games to captivate and } \\
\text { engage end-users for a specific purpose, such as to develop new } \\
\text { knowledge and skills }\end{array}$ & Corti & 2006 & Serious Games \\
\hline 10 & $\begin{array}{l}\text { provide structured and immersive problem-solving experiences } \\
\text { that enable the development of both knowledge and 'ways of } \\
\text { knowing' to be transferred to the situations outside of the original } \\
\text { context of gaming or learning }\end{array}$ & $\begin{array}{l}\text { Ke (citing } \\
\text { Shaffer) }\end{array}$ & $\begin{array}{l}2016 \\
(2006)\end{array}$ & $\begin{array}{l}\text { Learning } \\
\text { Games }\end{array}$ \\
\hline 11 & the design goal of designing for gamefulness & Deterding et al & 2011 & $\begin{array}{l}\text { Gameful } \\
\text { Design }\end{array}$ \\
\hline 12 & use of game design elements in non-game contexts & Deterding et al & 2011 & Gamification \\
\hline 13 & the design strategy of using game design elements & Deterding et al & 2011 & Gamification \\
\hline 14 & $\begin{array}{l}\text { activity structures in which players use a body of knowledge or set } \\
\text { of skills as resources in their competition with other players }\end{array}$ & $\begin{array}{l}\text { Devries and } \\
\text { Edwards }\end{array}$ & 1973 & $\begin{array}{l}\text { Learning } \\
\text { Games }\end{array}$ \\
\hline 15 & $\begin{array}{l}\text { designing systems that are intrinsically motivating and fun to use, } \\
\text { by applying those techniques that game designers use to keep } \\
\text { the players immersed and engaged }\end{array}$ & Dichev et al. & 2014 & $\begin{array}{l}\text { Gameful } \\
\text { Design }\end{array}$ \\
\hline 16 & $\begin{array}{l}\text { The use of game design elements in non-game contexts with the } \\
\text { goal of achieving long-term effects based on intrinsic motivation }\end{array}$ & Diewald et al. & 2013 & $\begin{array}{l}\text { Gameful } \\
\text { Design }\end{array}$ \\
\hline 17 & $\begin{array}{l}\text { any piece of software that merges a non-entertaining purpose } \\
\text { (serious) with a video game structure (game). }\end{array}$ & Djaouti et al. & 2011 & Serious Games \\
\hline 21 & $\begin{array}{l}\text { computer games developed for educational use or titles often } \\
\text { finding their way to educational settings both the fake, bad, } \\
\text { ambitious and superb }\end{array}$ & $\begin{array}{l}\text { Egenfeldt- } \\
\text { Nielsen }\end{array}$ & 2005 & $\begin{array}{l}\text { Educational } \\
\text { Computer } \\
\text { Games }\end{array}$ \\
\hline 20 & $\begin{array}{l}\text { Traditional non-electronic game-like activities developed for } \\
\text { educational use spanning board games, simulations, role-playing } \\
\text { games etc. }\end{array}$ & $\begin{array}{l}\text { Egenfeldt- } \\
\text { Nielsen }\end{array}$ & 2005 & $\begin{array}{l}\text { Educational } \\
\text { Games }\end{array}$ \\
\hline
\end{tabular}


a sub-group of educational computer games that are heavily criticized. Typically edutainment titles are characterized by using

19 quite conventional learning theories, providing a questionable game experience, simple gameplay and often produced with reference to a curriculum

18 the overarching perspective of games for something else than just entertainment games which provide users with specific skills development or

22 reinforcement learning within an entertainment setting, where skil development is an integral part of product

23 a type of computer-based instruction designed to motivate the gamer using game characteristics any interactive, digital game that is designed specifically to

24 facilitate the achievement of a specified set of learning outcomes that meet educational goals

a form of service packaging where a core service is enhanced by a rules-based service system that provides feedback and interaction mechanisms to the user with an aim to facilitate and support the users' overall value creation

26 a process of enhancing a service with affordances for gamefu experiences in order to support user's overall value creation use of gaming attributes (assigned challenge and a compelling

27 form of positive and/or negative reward system) to overcome a designated problem or deficiency, and provide appropriate feedback to the user about their efforts.

using game-based mechanics, aesthetics and game thinking to

28 engage people, motivate action, promote learning, and solve problems.

the use of ideas and ways of thinking that are inherent in games.

29 Game inspired design does not express in adding game elements, but rather in using of playful design. games designed for a specific purpose related to training, not just

30 for fun. They possess all game elements, they look like games, but their objective is to achieve something that is predetermined. games that targets the acquisition of knowledge as its own end

31 and foster cognition that is either generally useful or useful within an academic context

32 the phenomenon of creating gameful experiences the use of game metaphors, game elements and ideas in a

33 context different from that of the games in order to increase motivation and commitment, and to influence user behavior a collective term referring to digital games that are purposefully designed to help players learn about a particular topic. A digital game is an interactive form of entertainment in which a player's experience is mediated by computer software.

35 games that do not have entertainment, enjoyment, or fun as their primary purpose a sub-category of serious games. They do not only focus on imparting knowledge and raising awareness about a topic or an issue, but also on attitude or behavior change in a desirable direction, e.g. towards a more healthy lifestyle

37 The use of computer game and simulation approaches and/or technologies for primarily non- entertainment purposes

Egenfeldt-

Nielsen

2005

Edutainment

EgenfeldtNielsen

2005

Serious Games

ESRB

2013

Edutainment

Hannafin \& Peck 1988

Edutainment

Hirumi et al

2010

Instructional

Games

Huotari and

Hamari

2011

Gamification

Huotari and

Hamari

2012

Gamification

Susi et al. (cited

from I/ITSEC

Conference)

2007

(2006)

Serious Games

Kapp

2012

Gamification

(

Kiryakova et al $2014 \quad$ Gameful

Kiryakova et al $2014 \quad$ Serious Games

Klopfer et al. $2009 \quad$ Learning

$\begin{array}{lll}\text { Koivisto \& } & 2014 \quad \text { Gamification } \\ \text { Hamari }\end{array}$

Hamari

Marczewski

2013

Gamification

$\begin{array}{lll}\text { Martinez-Garza } & 2015 & \begin{array}{l}\text { Games for } \\ \text { Learning }\end{array}\end{array}$

Michael \& Chen 2005

Serious Games

Orji et al $2013 \quad \begin{aligned} & \text { Persuasive } \\ & \text { Games }\end{aligned}$

any marriage of educational content and computer games; any learning game on a computer or online

simple gameplay to support productive interaction for expected types of learners and instructors

Corti

2006

Serious Games games specifically designed for learning as opposed to the use of

40 games in learning

a learning process that uses as the main pedagogical tool a specific game which helps to arise and develop skills

\begin{tabular}{lcl} 
Prensky & 2001 & $\begin{array}{l}\text { Digital Game } \\
\text { Based } \\
\text { Learning }\end{array}$ \\
\hline Rughiniș & 2013 & $\begin{array}{l}\text { Gamification } \\
\text { (of education) }\end{array}$ \\
\hline Slussaref et al & 2016 & $\begin{array}{l}\text { Games for } \\
\text { Learning }\end{array}$ \\
Sousa \& Rocha & 2017 & $\begin{array}{l}\text { Game-based } \\
\text { Learning }\end{array}$ \\
\hline
\end{tabular}




\begin{tabular}{|c|c|c|c|c|}
\hline 42 & $\begin{array}{l}\text { games that engage the user, and contribute to the achievement of } \\
\text { a defined purpose other than pure entertainment (whether or not } \\
\text { the user is consciously aware of it) }\end{array}$ & Susi et al & 2007 & Serious Games \\
\hline 43 & $\begin{array}{l}\text { a branch of serious games that deals with applications that have } \\
\text { defined learning outcomes }\end{array}$ & Susi et al & 2007 & $\begin{array}{l}\text { Game-based } \\
\text { Learning }\end{array}$ \\
\hline 44 & $\begin{array}{l}\text { a class of games in which people, as a side effect of playing, } \\
\text { perform tasks computers are unable to perform }\end{array}$ & $\begin{array}{l}\text { Von Ahn \& } \\
\text { Dabbish }\end{array}$ & 2008 & $\begin{array}{l}\text { Games with a } \\
\text { Purpose }\end{array}$ \\
\hline 45 & game applications that have defined learning outcomes & $\begin{array}{l}\text { Von } \\
\text { Wangenheim \& } \\
\text { Shull }\end{array}$ & 2009 & $\begin{array}{l}\text { Game-based } \\
\text { Learning }\end{array}$ \\
\hline 46 & the process of making activities more game-like & Werbach & 2014 & Gamification \\
\hline 47 & $\begin{array}{l}\text { game-design elements are added in the hopes of incentivizing a } \\
\text { particular process thereby adding intrinsic motivation in a given } \\
\text { gamified process which invariably uses extrinsic rewards }\end{array}$ & Wiggins & 2016 & Gamification \\
\hline 48 & $\begin{array}{l}\text { games are used in the classroom to enhance learning and } \\
\text { teaching; the use of actual games in education; the intentional use } \\
\text { of digital or non-digital games or simulations for the purpose of } \\
\text { fulfilling one or more specific learning objectives }\end{array}$ & Wiggins & 2016 & $\begin{array}{l}\text { Game-based } \\
\text { Learning }\end{array}$ \\
\hline 49 & $\begin{array}{l}\text { the outcome of integrating effective learning principles into game } \\
\text { environments for the purpose of utilizing engaging elements of } \\
\text { games as a means for improving the quality of education }\end{array}$ & Wu et al. & 2012 & $\begin{array}{l}\text { Game-assisted } \\
\text { Learning }\end{array}$ \\
\hline 50 & $\begin{array}{l}\text { a mental contest, played with a computer in accordance with } \\
\text { specific rules, that uses entertainment to further government or } \\
\text { corporate training, education, health, public policy, and strategic } \\
\text { communication objectives }\end{array}$ & Zyda & 2006 & Serious Games \\
\hline
\end{tabular}

\section{A.1. Definitions Bibliography}

- Abt, C. C. (1968). Games for learning. In Simulation games in learning (pp. 65-84).

- Abt, C. C. (1970). Serious Games. Viking

- Annetta, L. A. (Ed.). (2008). Serious Educational Games: From Theory to Practice. Sense.

- Annetta, L. A. (2010). The "I's" have it: A framework for serious educational game design. Review of General Psychology, 14(2), 105-112.

- Bellotti, F., Berta, R., De Gloria, A., Ott, M., Arnab, S., de Freitas, S., \& Kiili, K. (2011). Designing Serious Games for Education: from Pedagogical principles to Game Mechanisms. In Proceedings of the 5th European Conference on Games Based Learning (Vol. 2, pp. 1-9). Academic Publ. Ltd.

- Bellotti, F., Kapralos, B., Lee, K., Moreno-Ger, P., Berta, R., \& Barreto, A. B. (2013). Assessment in and of Serious Games: An Overview. Advances in Human-Computer Interaction, 11. https://doi.org/10.1155/2013/136864

- Buckingham, D., \& Scanlon, M. (2000). That is edutainment: media, pedagogy and the market place. In International Forum of Researchers on Young People and the Media, Sydney.

- Cook, D. (2005). Serious Games: A broader definition. Retrieved September 5, 2017, from http://www.lostgarden.com/2005/05/serious-gamesbroader-definition.html

- Corti, K. (2006). Games-based Learning: a serious business application. PIXELearning (Vol. 34(6)).
- Deterding, S., Dixon, D., Khaled, R., \& Nacke, L. (2011). From Game Design Elements to Gamefulness: Defining "Gamification"

- Dichev, C., Dicheva, D., Angelova, G., \& Agre, G. (2014). From gamification to gameful design and gameful experience in learning. Cybernetics and Information Technologies, 14(4), 80-100.

- Diewald, S., Möller, A., Roalter, L., Stockinger, T., \& Kranz, M. (2013, October). Gameful design in the automotive domain: review, outlook and challenges. In Proceedings of the 5th International Conference on Automotive User Interfaces and Interactive Vehicular Applications (pp. 262-265). ACM.

- Djaouti, D., Alvarez, J., \& Jessel, J.-P. (2011). Classifying serious games: The G/P/S model. In Handbook of research on improving learning and motivation through educational games: Multidisciplinary approaches (pp. 118-136). https://doi.org/10.4018/978-1-60960-495-0.ch006

- Egenfeldt-Nielsen, S. (2005). Beyond Edutainment: Exploring the Educational Potential of Computer Games.

- Entertainment Software Rating Board. (2013). Entertainment Software Rating Board. Retrieved September 5, 2017, from http://www.esrb.org/ratings/ratings_guide_gamecent er.aspx

- Hannafin, M. J., \& Peck, K. L. (1988). The design, development, and evaluation of instructional software. Macmillan.

- Hirumi, A., Appelman, B., Rieber, L., \& Van Eck, R. (2010). Preparing Instructional Designers for GameBased Learning: Part 1. TechTrends, 54(4), 27-38. 
- Huotari, K., \& Hamari, J. (2011). "Gamification" from the perspective of service marketing. CHI 2011 Workshop Gamification, (January), 11-15. https://doi.org/table of contents ISBN: 978-1-45031637-8 doi $>10.1145 / 2393132.2393137$

- Huotari, K., \& Hamari, J. (2012). Defining gamification. In Proceeding of the 16th International Academic MindTrek Conference on - MindTrek '12 (p. 17). https://doi.org/10.1145/2393132.2393137

- Kapp, K. M. (2012). The Gamification of Learning and Instruction: Game based methods and strategies for training and instruction. Wiley.

- Ke, F. (2016). Designing and integrating purposeful learning in game play: a systematic review. Educational Technology Research and Development, 64(2), 219-244.

- Kiryakova, G., Angelova, N., \& Yordanova, L. (2014). Gamification in Education. Proceedings of the 9th International Balkan Education and Science Conference.

- Klopfer, E., Osterweil, S., \& Salen, K. (2009). Moving learning games forward. Cambridge, MA: The Education Arcade.

- Koivisto, J., \& Hamari, J. (2014). Demographic differences in perceived benefits from gamification. Computers in Human Behavior, 35, 179-188.

- Marczewski, A. (2013). What's the difference between Gamification and Serious Games? Retrieved August 30, 2017, from https://www.gamasutra.com/blogs/AndrzejMarczews ki/20130311/188218/Whats_the_difference_between Gamification_and_Serious_Games.php

- Martinez-Garza, M. M., \& Clark, D. B. (2015). Games for Learning. In Encyclopedia of Science Education (pp. 437-440).

- McIntosh, C., Willis, J., \& Girbau, N. M. (Eds.). (2017). Cambridge Business Dictionary: Meanings \& Definitions. Dictionary.cambridge.org.

- Michael, D. R., \& Chen, S. L. (2006). Serious Games: Games That Educate, Train, and Inform. Thomson Course Technology.

- Orji, R., Mandryk, R. L., Vassileva, J., \& Gerling, K. M. (2013). Tailoring persuasive health games to gamer type. Proceedings of the SIGCHI Conference on Human Factors in Computing Systems - CHI '13, 2467-2476.

https://doi.org/10.1145/2470654.2481341

- Prensky, M. (2001). Digital Game-Based Learning. New York: McGraw-Hill.

- Rughiniș, R. (2013). Gamification for Productive Interaction Reading and Working with the Gamification Debate in Education. The 8th Iberian Conference on Information Systems and Technologies CISTI 2013, 1-5.

- Shaffer, D. W. (2006). Epistemic frames for epistemic games. Computers and Education, 46(3), 223-234. https://doi.org/10.1016/j.compedu.2005.11.003
- Slussareff, M., Braad, E., Wilkinson, P., \& Strååt, B. (2016). Games for Learning. In Entertainment Computing and Serious Games (pp. 189-211). Springer, Cham.

- Sousa, M. J., \& Rocha, Á. (2017). Game based learning contexts for soft skills development. Advances in Intelligent Systems and Computing, 570, 931-940. https://doi.org/10.1007/978-3-319-565385_92

- Susi, T., Johannesson, M., \& Backlund, P. (2007). Serious Games - An Overview. Elearning (Vol. 73)

- von Ahn, L., \& Dabbish, L. (2008). Designing games with a purpose. Communications of the ACM, 51(8), 57. https://doi.org/10.1145/1378704.1378719.

- von Wangenheim, C. G., \& Shull, F. (2009). To game or not to game? IEEE Software, 26(2), 92-94.

- Werbach, K. (2014). (Re)Defining Gamification: A Process Approach. In International Conference on Persuasive Technology (pp. 266-272). Springer, Cham. https://doi.org/10.1007/978-3-319-071275_23

- Wiggins, B. E. (2016). An Overview and Study on the Use of Games, Simulations, and Gamification in Higher Education. International Journal of GameBased Learning, 6(1), 18-29. https://doi.org/10.4018/IJGBL.2016010102

- Wu, W. H., Hsiao, H. C., Wu, P. L., Lin, C. H., \& Huang, S. H. (2012). Investigating the learning-theory foundations of game-based learning: A meta-analysis. Journal of Computer Assisted Learning, 28(3), 265279.

- Zyda, M. (2005). From visual simulation to virtual reality to games. Computer, 38(9), 25-32.

\section{References}

[1] Gordon, A. K. (1970). Games For Growth; Educational Games in the Classroom. Science Research Associates, Inc., College Division, 1540 Page Mill Road, Palo Alto, California 94304

[2] Breuer, J., \& Bente, G. (2010). Why so serious? On the relation of serious games and learning. Eludamos. Journal for Computer Game Culture, 4(1), 7-24.

[3] Wilkinson, A. M. (1991). The scientist's handbook for writing papers and dissertations. Prentice Hall PTR.

[4] Blank, A. (1999). Why Do New Meanings Occur?: A Cognitive Typology of the Motivations for Lexical Semantic Change. In Historical Semantics and Cognition (pp. 61-89).

[5] Caponetto, I., Earp, J., \& Ott, M. (2014). Gamification and Education: A Literature Review. In Proceedings of the European 8th Conference on Games Based Learning (Vol. 1, pp. 50-57).

[6] Wessa, P., \& Office for Research Development and Education. (2017). Hierarchical Clustering (v1.0.4) in Free Statistics Software (v1.2.1).

[7] Abt, C. C. (1970). Serious Games. Viking

[8] Wilkinson, P. (2016). Brief history of serious games. In Lecture Notes in Computer Science (including subseries 
Lecture Notes in Artificial Intelligence and Lecture Notes in Bioinformatics) (Vol. 9970 LNCS, pp. 17-41).

[9] Michael, D. R., \& Chen, S. L. (2006). Serious Games: Games That Educate, Train, and Inform. Thomson Course Technology.

[10] Egenfeldt-Nielsen, S. (2005). Beyond Edutainment: Exploring the Educational Potential of Computer Games.

[11] Zyda, M. (2005). From visual simulation to virtual reality to games. Computer, 38(9), 25-32.

[12] Corti, K. (2006). Games-based Learning: a serious business application. PIXELearning (Vol. 34(6)).

[13] Susi, T., Johannesson, M., \& Backlund, P. (2007). Serious Games - An Overview. Elearning (Vol. 73).

[14] Annetta, L. A. (2010). The "I's" have it: A framework for serious educational game design. Review of General Psychology, 14(2), 105-112.

[15] Bellotti, F., Berta, R., De Gloria, A., Ott, M., Arnab, S., de Freitas, S., \& Kiili, K. (2011). Designing Serious Games for Education: from Pedagogical principles to Game Mechanisms. In Proceedings of the 5th European Conference on Games Based Learning (Vol. 2, pp. 1-9). Academic Publ. Ltd.

[16] Djaouti, D., Alvarez, J., \& Jessel, J.-P. (2011). Classifying serious games: The G/P/S model. In Handbook of research on improving learning and motivation through educational games: Multidisciplinary approaches (pp. 118-136). https://doi.org/10.4018/978-1-60960-495-0.ch006

[17] Kiryakova, G., Angelova, N., \& Yordanova, L. (2014). Gamification in Education. Proceedings of the 9th International Balkan Education and Science Conference.

[18] Annetta, L. A. (Ed.). (2008). Serious Educational Games: From Theory to Practice. Sense.

[19] Prensky, M. (2001). Digital Game-Based Learning. New York: McGraw-Hill

[20] von Wangenheim, C. G., \& Shull, F. (2009). To game or not to game? IEEE Software, 26(2), 92-94.

[21] Wu, W. H., Hsiao, H. C., Wu, P. L., Lin, C. H., \& Huang, S. H. (2012). Investigating the learning-theory foundations of game-based learning: A meta-analysis. Journal of Computer Assisted Learning, 28(3), 265-279.

[22] Hirumi, A., Appelman, B., Rieber, L., \& Van Eck, R. (2010). Preparing Instructional Designers for Game-Based Learning: Part 1. TechTrends, 54(4), 27-38.

[23] Hirumi, A., Appelman, B., Rieber, L., \& Van Eck, R. (2010). Preparing Instructional Designers for Game-Based Learning: Part 2. TechTrends, 54(4), 19-27.

[24] Hirumi, A., Appelman, B., Rieber, L., \& van Eck, R. (2010). Preparing Instructional Designers for Game-Based Learning: Part III: Game Design as a Collaborative Process. TechTrends, 54(5), 38-45.

[25] Abt, C. C. (1968). Games for learning. In Simulation games in learning (pp. 65-84).

[26] Slussareff, M., Braad, E., Wilkinson, P., \& Strååt, B. (2016). Games for Learning. In Entertainment Computing and Serious Games (pp. 189-211). Springer, Cham.

[27] Deterding, S., Dixon, D., Khaled, R., \& Nacke, L. (2011). From Game Design Elements to Gamefulness: Defining "Gamification"

[28] Hecker, C. (2010). Achievements considered harmful. GDC 2010.

[29] Rughiniş, R. (2013). Gamification for Productive Interaction Reading and Working with the Gamification Debate in Education. The 8th Iberian Conference on Information Systems and Technologies CISTI 2013, 1-5.

[30] Gredler, M. (2009). Learning and instruction: Theory into Practice. Learning and Instruction
[31] Bogost, I. (2007). Persuasive Games: The Expressive Power of Videogames. Literary Linguistic Computing (Vol. 23).

[32] Deterding, S. (2013). Gameful Design for Learning. T \& D, (July 2013).

[33] Diewald, S., Möller, A., Roalter, L., Stockinger, T., \& Kranz, M. (2013, October). Gameful design in the automotive domain: review, outlook and challenges. In Proceedings of the 5th International Conference on Automotive User Interfaces and Interactive Vehicular Applications (pp. 262-265). ACM.

[34] Dichev, C., Dicheva, D., Angelova, G., \& Agre, G. (2014). From gamification to gameful design and gameful experience in learning. Cybernetics and Information Technologies, 14(4), 80-100.

[35] Seaborn, K., \& Fels, D. I. (2015). Gamification in theory and action: A survey. International Journal of humancomputer studies, 74, 14-31.

[36] Ke, F. (2016). Designing and integrating purposeful learning in game play: a systematic review. Educational Technology Research and Development, 64(2), 219-244

[37] Crookall, D. (2010). Serious Games, Debriefing, and Simulation/Gaming as a Discipline. Simulation \& Gaming, 41(6), 898-920.

[38] Griepp, M. (2016). Hobby Games Market Hits \$700M. ICV2.

[39] Boocock, S. S., \& Schild, E. (Eds.). (1968). Simulation Games in Learning. Sage Publications, Inc. 